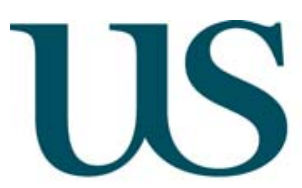

\title{
University of Sussex
}

Business, Management \& Economics

\section{Ecomomics Department Working Paper Series}

\author{
No. 31-2012
}

\section{Assessing the Trade Impact of the European Neighborhood Policy on EU-MED Free Trade Area}

\author{
Pierluigi Montalbano \\ University of Sussex and Sapienza University \\ p.montalbano@sussex.ac.uk \\ Silvia Nenci \\ University of Roma Tre \\ snenci@uniroma3.it
}

\begin{abstract}
The goal of this paper is to provide an "ex ante" assessment of the long-run "treatment" effect of ENP on EU-MED Free Trade Area. Supplementary objectives are the presentation of new up-to-date "in-sample" estimates of the actual trade potential in the Pan-european Common Market as well as more robust estimates of the trade enhancing impact of EU deep integration policy. The novel aspect of this work is twofold: i) to present nonparametric matching estimators along with gravity estimates; ii) to assume, as a counterfactual (i.e., the hypothetical situation of ENP full implementation), the ex-post long-run average treatment effect of the Europe Agreements, which are the unique experience to date of "full partnership without membership". Our empirical outcomes show a likely strong and robust impact on EU-MED trade integration of the new "deep integration" efforts made by the EU. This is confirmed by both the applied dummy strategy and the non parametric matching technique. This result seems to be linked to other factors than simply trade preferences alone. Our empirical evidence is relevant both to policymaking, since it provides an "ex ante" assessment of the efficacy of deep integration under the EU-MED regional cooperation framework, and to the methodological point of view, since it contributes to improvements in empirical estimates of the "policy impact" of EU preferential agreements.
\end{abstract}

JEL Classification: F13, F15, F17, 052

Key Words: Trade policy, European integration, Gravity Model, Matching econometrics, Southern Mediterranean Countries

Acknowledgement: The authors are grateful to the participants at the AISSEC Conference (Macerata, June 2011) and at ETSG Conference (Copenhagen, September 2011). A special thank goes to Luca Salvatici for helpful comments and advice and to Emiliano Magrini for his valuable research assistance. The usual disclaimers apply. 


\section{Introduction}

The European Neighborhood Policy (ENP) set an additional objective for the Southern Mediterranean Countries (SMCs): the prospect of "a stake in the internal market" together with further integration with European Union (EU) member countries in order to promote the free movement of people, goods, services and capital ${ }^{1}$. The novelty of ENP consists precisely in its goal of achieving the so-called Deep and Comprehensive Free Trade Area (DCFTA) with EU neighbors by moving from a process of "negative integration" (i.e., gradual dismantling of trade barriers) towards a process of "positive integration" (i.e., regulatory convergence in areas that have an impact on trade, in particular sanitary and phytosanitary rules, customs and border procedures, competition and public procurement). For the most advanced partners this could lead to a progressive economic integration with the EU internal market under the slogan "full partnership without membership" (EC, 2011), but will it work? At a point now halfway through the first phase of the ENP process (which lasts from 2007 to 2013), and with the prospect of further implementation in the near future because of the urgent need of political stabilization in the Mediterranean area, we still lack a thorough analysis of the actual impact of the policy.

The goal of this paper is to provide an "ex ante" assessment of the long-run average (partial) treatment effect of ENP on the EU-MED Free Trade Area (FTA) process, i.e., to investigate if deep integration in the Mediterranean area represents "a boost" in the implementation of the on-going EU-MED FTA. In this paper, notwithstanding we acknowledge the presence of long-run general equilibrium effects too (Anderson and van Wincoop, 2003; Bergstrand et al., 2007), following Baier and Bergstrand (2009) we focus rather on the long-run partial or "treatment" effects of the policy. ${ }^{2}$ Hence, differently from standard analysis, our "ex ante" evaluation does not rely on computable general equilibrium models of trade, rather on assuming a "treatment" counterfactual (i.e., the hypothetical situation of ENP full implementation), such as the ex-post longrun average (partial) treatment effects of the Europe Agreements, which are the unique experience of "full partnership without membership" to date. Supplementary objectives are to present up-to-date "in-sample" estimates of the actual trade gaps in the Mediterranean Area as well as new reliable estimates of the EU policy impact on trade in the area.

This work follows up on the large amount of empirical literature aimed at

\footnotetext{
${ }^{1}$ The European Neighborhood Policy was launched by the EU in 2004 with the objective of strengthening the link between the enlarged EU and its neighbors and of promoting prosperity, stability and security of all. The ENP is addressed to the following neighbors: Algeria, Armenia, Azerbaijan, Belarus, Egypt, Georgia, Israel, Jordan, Lebanon, Libya, Moldova, Morocco, Occupied Palestinian Territory, Syria, Tunisia and Ukraine. It is primarily a bilateral policy and offers to the EU neighbors a mutual commitment to common values, such as democracy and human rights, rule of law, good governance, market economy principles and sustainable development. The Commission already made proposals to strengthen this policy in the future.

${ }^{2}$ These estimated effects could be eventually combined with a non linear system of structural equations to generate general-equilibrium comparative statics, as done by Anderson and van Wincoop (2003) and Bergstrand et al. (2007).
} 
assessing the impact of the EU-MED FTA on bilateral trade. The launch of ENP has been the occasion for a revival of these empirical studies aimed at testing the actual dimension of unexploited trade as well as the level of trade potential once the "new generation" of EU-MED Free Trade Agreements (FTAs) are implemented. Thanks to its wide empirical applicability as well as its robust theoretical foundations, the gravity model is the workhorse of this strand of applied literature. The novel approach of this work with respect to the existing literature is twofold: i) to present nonparametric matching estimators along with gravity estimates; ii) to assume the ex-post long-run average (partial) treatment effects of the Europe Agreements (EAs) as a counterfactual. Furthermore, while the previous empirical works normally rely on "out-of-sample" estimates (i.e., using parameters estimated in samples of already highly integrated countries) ${ }^{3}$, this work attempts to overcome this weakness by relying on the parameters estimated from panel data of the sample of countries actually involved in the ENP process. To sum up, our model provides more robust "ex post" estimates of the EAs treatment effect as well as a workable simulation of the likely impact of ENP. This is justified by the fact the ENP is deliberately inspired by EAs and adopts similar tools. ${ }^{4}$

To overcome the well known trade off between the statistical accuracy of the estimates and their policy relevance, we propose a set of alternative strategies able to provide a more robust assessment of the EU "treatment effect" on EU-MED integration. Specifically, we present three alternative strategies: i) a dummy strategy, the standard way to estimate the causal average treatment effect of trade policy on trade volumes; ii) a continuous variable strategy, able to quantify the true preferential margins guaranteed by the EU-MED preferential agreements; iii) a matching strategy, able to address the "non random selection bias" in the "treatment group" by generating new treatment and control groups selected on observable covariates. Each strategy is implemented under alternative specifications of the gravity estimates, such as the standard pool ordinary least squares (POLS) specification, and a combined fixed effects (CFE) specification, which includes all the main effects and interactions. Each of the above empirical specifications is provided for both the traditional and the so-called New Trade Theory (NTT) versions of the gravity model. In the spirit of the NTT literature (Krugman, 1980; Helpman and Krugman, 1985), the proposed NTT version of the gravity model is based on economies of scale combined with product differentiation and transportation costs. More precisely, following Helpman (1987), Bergstrand (1990), Hummels and Levinsohn (1995) and Baltagi et al. (2003), we include in this gravity model relative factor endowment differences, overall bilateral country size and similarity in country size.

Our empirical outcomes show a strong and robust policy impact of EU preferential agreements on EU-MED FTA. This is confirmed by the applied dummy

\footnotetext{
${ }^{3}$ It means to assume implicitly homogeneous patterns of trade integration across the samples.

${ }^{4}$ The only remarkable difference is that ENP does not end up with a full membership status. This could, in principle, generate differences in the implementation of the policy which are indeed unobservable.
} 
strategy and the non parametric matching technique, while, as expected, it is not the case for preferential margins. This suggests that trade policy per se is not the primary factor behind the observed trade expansion, and hence that the trade impact of EU efforts towards deep integration lies in factors other than trade preferences alone. This result is relevant both to policymaking, since it provides an "ex ante" assessment of the efficacy of the DCFTA under the EU-MED regional cooperation framework, and to the methodological point of view, since it contributes to improvements in empirical estimates of the "policy impact" of EU preferential agreements.

\section{What EU-MED partnership after ENP?}

As described previously, ENP complements the EU-MED partnership; the aim is to consolidate and not to replace it. Nevertheless, it marks a major breakthrough in the nature of EU-MED partnership: the acquis communautaire becomes the tool to create a Pan-European partnership without the cost of membership (Cardwell, 2011). To this aim the new European Neighborhood and Partnership Instrument (ENPI) is committed to transferring funding assistance of approximately 12 billion euros to the SMCs in the period 2007-2013.

The EU strategy is to offer political association, personal contacts and deeper economic integration to SMCs building on the existing EU-MED Association Agreements (AAs). One of the main ENP aims is to boost the EU-MED FTA by establishing a deep integration (the so called DCFTA). For the most advanced partners, it should lead to a progressive economic integration with the EU internal market (EC, 2011). The creation of the EU-MED FTA was the main economic target of the Barcelona Declaration (November, 27-28 1995). With this declaration, the EU set the ambitious aim of integrating 15 highly industrialized countries with 12 Mediterranean intermediate revenue primary resource based countries, by means of a set of Bilateral Association Agreements signed between the EU and the SMCs. The process is currently in place and nowadays includes about 40 countries and 800 million consumers. After the total removal of trade barriers in the EU-MED space, the Mediterranean Area will become one of the most important North-South trade bloc in the world. In principle DCFTA should enhance this widespread integration process - to be implemented in accordance with WTO multilateral rules - by adding regulatory convergence in areas that have an impact on trade (such as sanitary and phytosanitary rules, customs and border procedures, competition and public procurement, etc.) to the gradual dismantling of trade barriers

Over fifteen years after the launch of the Barcelona Process every Mediterranean country is involved in the EU-MED partnership ${ }^{5}$ except Syria (including

\footnotetext{
${ }^{5}$ The EU-Mediterranean Partnership was re-launched in 2008 as the Union for the Mediterranean with the aim of infusing new vitality into the Partnership and raising the political level of the strategic relationship between the EU and its Southern neighbors. The Partnership now includes all 27 member states of the European Union, together with 16 partners across the Southern Mediterranean and the Middle East.
} 
the Palestinian Authority holding an Interim Euro-Mediterranean Association Agreement). These agreements, which collectively replace the previous generation of cooperation agreements signed in the 1970s, cover a wide variety of economic, social, cultural and financial cooperation topics and constitute the foundation for the development of free trade in the Mediterranean region. Thanks to the EU-MED partnership, from 1995 to date, SMCs have registered a dramatic decrease in Most Favored Nations (MFN) customs duties. Their current tariffs with the EU are below 18 percent for agricultural products and 5 percent for non-agricultural products (Femise, 2011). The 42 members of the PanEuroMed system have also adopted a "PanEuroMed Protocol on cumulation of origin". This allows economic operators to cumulate processing made in different countries of the region and thus obtain preferential treatment. The conclusion of South-South FTAs among SMCs with the same origin protocol will effectively allow them to benefit from this facility. Liberalization of trade in agriculture is largely achieved as well. More than 80 percent of agricultural products imported from the Mediterranean countries enter the EU market either duty free or at reduced rates. Reciprocally, one third of EU exports of agricultural products benefits from preferential treatment in the Mediterranean countries. Liberalization of trade in services and investment, including the right of establishment, is also part of the Association Agreements' key objectives. The Istanbul Framework Protocol, endorsed in July 2004, defined the core principles of services liberalization, including a regional MFN clause to ensure the consistency and coherence of the bilateral agreements.

Indeed, the Barcelona process goes well beyond trade integration, including a real political project of co-development and shared prosperity supported by technical assistance, financial transfers and sub-national bilateral cooperation actions. In line with the priorities agreed on at the Barcelona Summit, the European Commission (EC) has also launched several initiatives to deepen trade liberalization, regulatory convergence and to strengthen legal framework. Notwithstanding the above achievements, EU-MED trade relations have worsened in relative terms. While EU trade flows have widened with China and North America, the relative performance of SMCs remains steady (Femise, volumes).

As previously described, the ENP aims to boost the EU-MED FTA by providing a policy anchor and a better environment for economic relations and standards' harmonization. It is deliberately inspired by the positive experience already made by EU in integrating the Central Eastern European Countries (CEECs) in the internal market during the pre-adhesion phase of the enlargement process. During this phase (which lasted almost 10 years, from 1995 to $2004^{6}$ ), CEECs shared the only experience to date of the EU concept of "full partnership without membership" by signing the so-called Europe Agreements (EAs). These agreements include the establishment of a political dialogue as well as forms of economic, cultural and financial cooperation including the creation of a free trade area. Even if trade policy were not the primary integration

\footnotetext{
${ }^{6}$ Except for Bulgaria and Romania that joined the EU in 2007.
} 
factor for CEECs, EAs did contain significant trade liberalization concessions, in particular the gradual dismantling of EU tariff barriers to CEECs' industrial exports. According to the EC, in principle the ENP should replicate the success of the new EU member states' transition process in the Mediterranean area. The EC believes that the ENP could overcome the current limits of the EU-MED partnership and foster the creation of a true Pan European Common Market. Critics claim that such expectations are overstated since neighborhood countries are poorer and more heterogeneous with respect to the new EU member states to follow the same path (Milcher et al., 2007). They also argue that ENP is unlikely to be seen as a fully satisfactory substitute for EU membership and that the ENP process should be seen rather as a way of spoiling SMCs chances for EU accession (Del Sarto and Schumacher, 2005). Moreover, strong reservations have been expressed by some EU member states to the idea of extending the entire EU acquis to SMCs. They fear that the new EU-MED integration process will imply a loss of EU competitiveness in a number of sectors (such as agriculture, textiles, services, etc.). At the same time SMC policymakers are concerned about the balance between the costs of aligning legislation and rules with the EU acquis and the future gains to be derived from their simple status as partners. Another trade off for SMCs is currently in place between the call for a deep integration in the framework of the European regional partnership and the effects of undertaking a process of multilateral trade liberalization. The latter could imply the same benefits without the cost of the trade diversion effects. As it is evident from the above, the debate is open. To assess the feasibility of the EC expectations about the trade potentials of ENP within the EU-MED partnership is the goal of this empirical exercise.

\section{The empirical model}

Since its introduction by Tinbergen (1962) and thanks to its robust theoretical foundations based on the seminal works of Helpman and Krugman (1985), Bergstrand (1985) and Deardorff (1997), the gravity model has been widely used for explaining international trade flows. One of the most prominent uses of the gravity equation has been to explain and predict the impacts of economic integration agreements on trade flows. Until recently, gravity analyses of patterns of trade in the context of the EU-MED partnership have been extensively carried out both to compute trade gaps between actual and potential flows and to predict the potential EU-MED trade flows after changes in trade policies (Abediny and Péridy, 2006; Ruiz and Villarubia, 2007; Pastore et al., 2009; CASE/CEPS, 2009; Hagemejer and Ciselik, 2009; Bensassi et al., 2009; Jarreau, 2011). However, these empirical works usually rely on dummy variables to capture the economic impacts of alternative trade policies whose significance tends to decline in magnitude the more one controls for heterogeneity in the model, becoming statistically insignificant when a full set of interactions is applied (De Benedictis and Vicarelli, 2005; Stack, 2009; Hornok, 2011; De Benedictis and Taglioni, 2011). Furthermore, they normally rely on "out-of-sample" trade po- 
tential estimates - i.e. parameters for highly integrated countries are applied to project "natural" trade relations between out of sample benchmark countries and countries starting to integrate.

The aim of this empirical exercise is twofold: first to simulate the likely policy impact of deep integration ensured by ENP on the EU-MED FTA by presenting nonparametric matching estimators along with gravity estimates; second to update the extensive gravity literature on EU-MED actual unexploited trade with new "in-sample" estimates. This is now feasible since it is more than 15 years since the launch of the new EU-MED partnership by the Barcelona Declaration.

The added value of this work is to show the policy relevance of ENP on EU-MED partnership by using the "treatment effect" of EAs as a counterfactual, along with controlling for country and time heterogeneity and trade costs endogeneity, and using both qualitative and quantitative measures of the policy variable. As already highlighted, EAs signatory CEECs shared - before the accession- exactly the "full partnership without membership" status which is currently the new target posed by ENP to the EU-MED partnership. Hence, the "ex post" assessment of the "treatment effect" on CEECs can be applied to assess "ex ante" and "ceteris paribus" the long-run treatment effect of ENP, once controlled for the usual supply and demand factors, as well as for country and time heterogeneity. In performing our empirical tasks, we acknowledge that the most recent gravity specifications - which use fixed effects to proxy unobserved trade costs (or MR index as Anderson and van Wincoop, 2003 put it) and an interaction effects design (Baltagi et al., 2003) - tend to underestimate the above policy effect (De Benedictis and Vicarelli, 2005; Stack, 2009; Hornok, 2011; De Benedictis and Taglioni, 2011).This is a serious drawback of this kind of analysis, since the more one controls for heterogeneity, the less one is able to capture the policy effect of interest. To overcome this methodological caveat we propose a set of alternative strategies to assess the long-run average (partial) treatment effect of the EU policy on the EU-MED partnership.

We start assessing the "treatment effect" by applying a simple dummy strategy. This is in fact the most workable solution, even if unsatisfactory for a number of reasons: it implicitly assumes equal treatment and does not control for gradual implementation of the agreements; it does not control for specific country pair events contemporaneous with FTA; it is unstable and looses significance the more one controls for heterogeneity in the model. This first strategy is though here presented exclusively as a matter of comparison with the other strategies and will act as our baseline scenario.

To get a more appropriate assessment of the "policy treatment" we perform two additional alternative strategies. One tentative strategy is to focus on the measures of trade policy actually embodied in Europe agreements. By confronting the results under this strategy with the dummy baseline scenario one can assess the presence and the relevance of additional factors other than trade policy in fostering trade flows. This strategy is particularly helpful in assessing the impact of deep integration. To this end, we apply a continuous variable strategy able to assess the actual "preferential margins" guaranteed by 
EU trade policy in the area. This strategy solves a number of weaknesses linked to the baseline dummy strategy, namely: it considers both the presence of differentiated treatments as well as the issue of the gradual implementation of the agreements. The issue of properly measuring the so-called "preferential margins" and hence assessing the relative market access conditions across countries is one of the hottest in current applied literature on trade liberalization and integration (see, inter alia, Anderson and Neary, 2003; Cipollina and Salvatici, 2010; Francois et al., 2006; Hoekman and Nicita, 2011; Kee et al., 2009). A number of complications arise when one tries to reach consensus both on an aggregate measure able to account properly for the complex structure of tariffs at the product level and on a true counterfactual of "no preference status". While, in fact, commonly used measures of preference margins compare the preferential tariff to the MFN rate, this risks an overestimate of the relative preference actually enjoyed by countries since it does not also take into account the likely preferential margins enjoyed by the other countries (Low et al., 2008; Hoekman and Nicita, 2011; Cipollina and Salvatici, 2011). Acknowledging the above caveats, we adopt a measure of relative preferential margin (RPM) calculated as the difference in percentage points between the "counterfactual" - computed as the average advantage granted by a given country to the exports originated in all the other countries in the sample - and the preferential tariff rate applied by the same country to the country under analysis. Tariffs are calculated as the weighted average (for all partner countries and all products) of the "effectively applied" tariff rates (AHS), i.e. the minimum tariff granted by a reporter.

A second alternative strategy is to employ a nonparametric matching estimator of EU policy effects. This strategy helps to distinguish more clearly the treatment from any other event specific to the country pairs. Moreover, it takes into account also the presence of non-linearities in the relationship between FTAs, trade flows and the other covariates, thanks to the use of a nonparametric matching equation (Baier and Bergstrand, 2009). Matching techniques are useful for addressing the likely self-selection bias traditionally linked to FTA treatment. In fact, countries that join an FTA are unlikely to be randomly chosen, but rather share the same characteristics used by the gravity equations to explain trade flows (Persson, 2001; Baier and Bergstrand, 2004; De Benedictis and Taglioni, 2011). Matching econometrics is able to build new "treatment" and "control" groups (i.e., country pairs that are virtually indistinguishable from treated pairs in terms of characteristics, except for the "policy treatment") by selecting on observable covariates. The standard assumption (i.e., the assumption of the conditional mean independence or ignorability of the treatment) is here addressed taking advantage of the theoretical robustness of the gravity equation as well as its recent empirical developments. Once the two groups are set, the actual allocation to a treatment or control group can be viewed as random and the average difference in trade flows between the pairs in the two groups can be taken as a robust estimate of the EU policy Average Treatment Effect (ATE). This method also provides a measure of the Average Treatment effect on the Treated (ATT), i.e., on countries sharing the FTA, which is the ac- 
tual target for policymakers. ${ }^{7}$ The solution of the non-random selection bias and the acceptance of non-linearity in the relationships among policy treatment, covariates and trade flows made by our nonparametric matching equation reduces the likely bias of FTA treatment effects induced by common gravity estimates (Baier and Bergstrand, 2009).

As is apparent, each of the above strategies adopt as a workhorse a robust specification of the gravity equation. It is common knowledge that the basic specification of the gravity model includes (Egger and Pfaffermayr, 2003): supply factors of the export country, demand factors of the import country, trade supporting and hampering factors (such as transport costs, geographical and cultural measures of bilateral proximity, etc.). Traditionally, the gravity model is linearized using a log-log equation and estimated using pooled ordinary least squares (POLS) techniques. Hence, the standard gravity equation takes the following form:

$\exp _{i j t}=\beta_{0}+\beta_{1} G D P_{i t}+\beta_{2} G D P_{j t}+\beta_{3} d i s t_{i j}+\beta_{4} a d j_{i j}+\beta_{5} l a n g_{i j}+\beta_{6} p_{i j t}+\varepsilon_{i j t}$

where all non-dummy variables are in natural logs. More specifically: $\exp _{i j t}$ are the bilateral export flows from country $i$ to country $j$ at time $t ; \beta_{0}$ is the intercept; $G D P_{i t}$ and $G D P_{j t}$ denote the economic size of the exporting and the importing countries, respectively; dist ${ }_{i j}$ is the geographic distance; $a d j_{i j}$ and $l_{a n g_{i j}}$ are binary-coded dummy variables reflecting adjoining land borders and common language, respectively (all the last three are used as proxy for transaction costs); $p_{i j t}$ is a set of binary-coded dummy variables reflecting trade integration agreements and represents the policy variable of interest; $\varepsilon_{i j t}$ is the random error.

This specification of the gravity equation has traditionally been used to explain the variation in bilateral trade flows among pairs of countries using cross-sectional data and has been widely applied by scholars in past attempts to assess the policy impact of the EU-MED partnership. However, it does not control for heterogeneity among countries. Furthermore, neither does it control for the endogeneity bias (i.e., reverse causality) possibly linked to unobserved trade costs (the "multilateral resistance issue", Anderson and van Wincoop, $2003)^{8}$. To address these issues, researchers have started to include a full set of fixed effects in the model (see Mátyás,1997; Feenstra, 2002; Egger, 2004; Baltagi et al., 2003; Egger and Pfaffermayr, 2003; Baldwin and Taglioni, 2007; Baier and Bengstrand, 2007). Moreover, panel estimation methods have been commonly used to avoid the problem of unobserved heterogeneity (see, among others, Wooldridge, 2000; Baier and Bergstrand, 2007; Baldwin and Taglioni,

\footnotetext{
${ }^{7}$ The aim is to identify the average treatment effect: $A T E=E\left[y_{1}-y_{0}\right]$ and especially the average treatment effect on the treated (ATT): $A T T=E\left[y_{1}-y_{0} \mid D=1\right]$. Both these measures are conditioned by the set of covariates $x$, as follows: $A T E=E\left[y_{1}-y_{0} \mid x\right]$ and $A T T=E\left[y_{1}-y_{0} \mid x, D=1\right]$

${ }^{8}$ The issue concerns the right way to proxy the bilateral trade barriers of two countries relative to their average trade barriers with all other trading partners.
} 
2006; Egger, 2000; Rose and van Wincoop, 2001; Glick and Rose 2001; Egger and Pfaffermayr, 2003). An up-to-date specification of the gravity equation is as follows:

$$
\exp _{i j t}=\alpha_{0}+\alpha_{1} G D P_{i t}+\alpha_{2} G D P_{j t}+\alpha_{3} p_{i j t}+\phi_{i}+\omega_{j}+\theta_{t}+\phi \omega_{i j}+\nu_{i j t}
$$

This specification, that we call Combined Fixed Effects (CFE) in this paper, includes, with respect to Eq. (1), the following main effects (Egger and Pfaffermayr, 2003): $\phi_{i}$ exporter-specific effects; $\omega_{j}$ importer-specific effects and $\theta_{t}$ time specific effect as well as the exporter-importer interaction $\phi \omega_{i j}$, the so-called country-pair fixed effect. The exporter and importer effects control for all time-invariant observable and unobservable country characteristics; time effects capture cyclical influences; the country pair effects account for "any time invariant geographical, historical, political, cultural influences which lead to deviations from a country pair's "normal" propensity to trade" (Egger and Pfaffermayr, 2003). The coefficients of these dummies should reflect the multilateral resistance term.

In this empirical exercise, we apply both the above gravity specifications (POLS and CFE) to provide alternative measures of the long run (partial) average treatment effect of the EU policy impact in the Mediterranean area.

Firstly, we apply a simple dummy strategy as baseline scenario for the subsequent analysis, testing the robustness of the following, binary-coded, dummy variables: $E U_{i j t} ; E A_{i j t}$ and $A A_{i j t} . E U_{i j t}$ is the standard dummy variable for European Union members. It takes value 1 in case of common membership of the EU, zero otherwise. $E A_{i j t}$ stands for Europe Agreements. It takes value 1 for bilateral trade between an EU member State and a partner country holding an Europe Agreement with the EU. It is time variant, covering the actual time period between the date each agreement came into force and its expiry date (see Table $1 \mathrm{~A}$ in the Appendix); $A A_{i j t}$ stands for the new Association Agreements signed by the EU with the SCMs. It takes value 1 for bilateral trade between an EU member State and a Mediterranean country holding an Association Agreement. It is also time variant, covering the actual time period after the date each Association Agreement came into force (see Table 2A in the Appendix). In this first empirical exercise, under the CFE specification ${ }^{9}$, our reference gravity equation becomes:

$$
\begin{aligned}
\exp _{i j t}= & \alpha_{0}+\alpha_{1} G D P_{i t}+\alpha_{2} G D P_{j t}+\alpha_{3} E U_{i j t}+\alpha_{4} E A_{i j t}+\alpha_{5} A A_{i j t}+(3) \\
& +\phi_{i}+\omega_{j}+\theta_{t}+\phi \omega_{i j}+\nu_{i j t}
\end{aligned}
$$

where the magnitude of the two parameters $\alpha_{4}$ and $\alpha_{5}$ represents, respectively, the long-run average (partial) treatment effect on bilateral trade flows of the Europe Agreements and the new Mediterranean Association Agreements.

\footnotetext{
${ }^{9}$ POLS case is easily derivable as well.
} 
Secondly, to address the continuous variable strategy, we provide an alternative version of the gravity equation capable of quantifying the aggregate preferential margin guaranteed by the EU preferential agreements to the non-EU partner countries in the sample. To this end, we test the magnitude and robustness of our measure of "relative preferential margin", $R P M_{j i t}$, computed as the difference - in percentage points - between the "counterfactual" (see above) and the "effectively applied" tariff rates (AHS) to bilateral trade flows ${ }^{10}$. Since in the case of SMCs, the differences between simple and weighted averages are the highest in the world (tariff levels are still too high on certain products and at the same time extremely low on others), we adopt the total weighted (with total imports) tariff average to take full account of the relative importance of trade policy. In this case, the ATE linked to the implementation of EU "preferential agreements" is derived by interacting the RPM with the presence of the EU preferential agreements under investigation $\left(p_{i j t}\right)$. Under the CFE specification, the gravity equation becomes ${ }^{11}$ :

$$
\begin{aligned}
\exp _{i j t}= & \alpha_{0}+\alpha_{1} G D P_{i t}+\alpha_{2} G D P_{j t}++\alpha_{3} R P M_{j i t}+\alpha_{4} R P M_{j i t} * p_{i j t}+(4) \\
& +\phi_{i}+\omega_{j}+\theta_{t}+\phi \omega_{i j}+\nu_{i j t}
\end{aligned}
$$

Finally, the gravity equation is used as treatment assignment equation in our nonparametric matching exercise. Following Baier and Bergstrand (2009), we use the Abadie and Imbens (2006) matching estimator (A-I) for the three nearest neighbors. The A-I estimator imputes the missing potential values of the "treatment" using average outcomes for country pairs with similar values for the gravity equation covariates ${ }^{12}$. Compared to the most common matching alternatives, this technique has the advantage of relying on a more precise matching procedure since it is not based on a single reference indicator (such as

\footnotetext{
${ }^{10}$ Data are from WITS. AHS tariff rate is equal to the MFN applied tariff unless a preferential tariff exists in the database

${ }^{11}$ POLS case is easily derivable as well.

${ }^{12}$ According to Abadie and Imbens (2006), the ATE estimator is $A T E_{M}=\frac{1}{N} \sum_{i=1}^{N}\left[T F_{i}^{*}(1)-\right.$ $\left.T F_{i}^{*}(0)\right]$ where $M$ stands for the number of matches per unit and $T F_{i}^{*}$ are the missing potential trade flows as follows:

$$
T F_{i}^{*}(1)=\left\{\begin{array}{c}
\frac{1}{M} \sum_{j \in J_{M(i)}} T F_{j}, \text { if FT } A_{i}=0 \\
T F_{i}, \text { if } F T A_{i}=1
\end{array}\right.
$$$$
T F_{i}^{*}(0)=\left\{\begin{array}{l}
\frac{1}{M} \sum_{j \in J_{M(i)}}^{T F_{i}, \text { if } F T A_{i}=0} T F_{j}, \text { ifFT } A_{i}=1
\end{array}\right.
$$

where $J_{M(i)}$ denotes the set of indices for the first M matches for unit $i$. Consistently, the ATT estimator is $A T T_{M}=\frac{1}{N} \sum_{F T A i=1}\left[T F_{i}-T F_{i}^{*}(0)\right]$. Since the number of matches increases with the sample size, there is little gain from using more than 3-4 matches. Under homoskedasticity, the variance goes down proportional to $\frac{1+1}{(2 M)}$ where $M$ is the number of matches.
} 
the propensity score), but on several covariates. This has an additional cost in managing the high dimensionality of the data.

All the alternative strategies for the assessment of the EU policy treatment effect in the Mediterranean area depicted above (dummy, continuos variable and matching estimator) are applied to specifications consistent with the New Trade Theory too. Following Helpman (1987), Bergstrand (1990), Hummels and Levinsohn (1995) and Baltagi et al. (2003), we include relative factor endowment differences, overall bilateral country size and similarity in country size in the NTT gravity model. This model also includes the following explanatory variables: the sum of the GDP of two countries as a measure of bilateral overall country size; a similarity index of the GDP of two trading partners as a measure of relative country size; and the absolute difference in relative factor endowments between two trading partners. According to this literature, equation 1 and 2 above can be amended as follows:

$$
\begin{aligned}
\exp _{i j t}= & \lambda_{0}+\lambda_{1} D G D P_{i j t}+\lambda_{2} S G D P_{i j t}+\lambda_{3} E G D P p c_{i j t}+ \\
& +\lambda_{4} d i s t_{i j}+\lambda_{5} a d j_{i j}+\lambda_{6} \operatorname{lang}_{i j}+\lambda_{7} p_{i j t}+\epsilon_{i j t} \\
\exp _{i j t}= & \gamma_{0}+\gamma_{1} D G D P_{i j t}+\gamma_{2} S G D P_{i j t}+\gamma_{3} E G D P p c_{i j t}+ \\
& +\gamma_{4} p_{i j t}+\phi_{i}+\omega_{j}+\theta_{t}+\phi \omega_{i j}+\mu_{i j t}
\end{aligned}
$$

The empirical results of both the standard and NTT versions of the gravity model provide a useful test of the robustness of the different strategies in evaluating the long run average (partial) treatment policy effects of different preferential agreements within the EU-MED trade integration process. Moreover, they provide us with a concrete measure of current unexploited trade in the EU-MED area as well as with useful insights into the likely evolution of potential trade within the EU-MED partnership in the case of full implementation of ENP. To fulfill this latter aim, we simulate the EU-MED trade flows by projecting ten years (to 2018) using the best parameters generated by our "in sample" estimates and assuming the "ex ante" average treatment effect of ENP to be proportional to the "ex post" average treatment effect of EAs (i.e., the unique example to date of EU "full partnership without membership" experiment). The outcomes of our empirical analysis and simulation are relevant both in terms of methodological updates and to an assessment of the actual efficacy of the new EU-MED framework after the implementation of ENP.

\section{Empirical results}

Our estimates (both standard and NTT) are applied to a sample of 42 reporting countries (the members of the European Economic Area plus Switzerland ${ }^{13}$,

\footnotetext{
${ }^{13}$ The European Economic Area (EEA) was established on 1 January 1994 following an agreement between the EU and the remaining members of the European Free Trade As-
} 
Central and Eastern European Countries, Southern Mediterranean Partners and the so-called New Independent States plus the Russian Federation) and 49 trading partners (the same reporter countries plus the main world partners), covering almost the total export flows originating from the EU-MED partnership area (a detailed list of countries included in the sample is provided in Table 3A in the Appendix). Nominal export flows are taken from the IMF Direction of Trade Statistics (DOTS) dataset, ${ }^{14}$ while data on Gross Domestic Products are from the World Bank, World Development Indicators database. Great circle distances and dummies for border and common language come from CEPII dataset. All monetary data are denominated in US current dollars and cover the period 1992-2008. ${ }^{15}$ Table 1 and Table 2 present the results for the standard and NTT specifications respectively of the gravity equation. As expected, in the baseline scenario (i.e., the dummy strategy) both the adjusted $\mathrm{R}^{2}$ values and RMSE tests confirm that the CFE specification is recommended as compared to POLS. Regarding the gravity parameters, all the coefficients have the expected signs. The positive and significant sign of the size-related coefficients confirms that economic size matters for trade. Regarding the relative endowment variables in the NTT model ("GDP pc difference" variable in Table 2), the sign supports the relevance of intra-industry trade within the EU-MED area. This is a somewhat unexpected outcome even if consistent with what had already happened in the case of the EU-CEECs trade flows. The time-invariant distance coefficients in the POLS specification have a negative sign, a relevant magnitude and a high statistical significance, as expected. The sign and magnitude of the adjacency and language dummies in the POLS specifications means that sharing a common border and speaking the same language implies higher bilateral trade than would otherwise be the case. The positive coefficient sign for the EA dummy across all specifications (it keeps its relevance and significance after controlling for country and time heterogeneity) confirms the trade-enhancing effect of the EU integration process towards CEECs. Conversely, the AA dummy presents a negative coefficient in all the gravity specifications, suggesting, as commonly stated by the empirical literature, a weakness in the Barcelona Agreements in enabling the removal of trading obstacles between MED and EU countries (Jar-

reau, 2011).

sociation (EFTA), except Switzerland (Iceland, Liechtenstein and Norway). It foresees the participation in the EU's Internal Market without a conventional EU membership.

${ }^{14}$ Since the percentage of zero flows represents only 10 percent of the total flows in our dataset, we did not consider them in the estimates .

${ }^{15}$ We have avoided updating our dataset with more recent export flow data because of their peculiar performance induced by the impact of the recent world economic crisis. 


\begin{tabular}{|c|c|c|c|c|}
\hline \multirow[b]{2}{*}{ Regressors } & \multicolumn{2}{|c|}{ Baseline } & \multicolumn{2}{|c|}{ Continuous variable } \\
\hline & OLSd & CFEd & OLScv & CFEcv \\
\hline \multirow[t]{2}{*}{ Exported GDP } & $1.116^{* * *}$ & $0.512^{* * *}$ & $1.143^{* * *}$ & $0.774^{* * *}$ \\
\hline & $(0.005)$ & $(0.038)$ & $(0.009)$ & $(0.082)$ \\
\hline \multirow[t]{2}{*}{ Importer GDP } & $0.809^{* * *}$ & $0.505^{* * *}$ & $0.804^{* * *}$ & $0.457^{* * *}$ \\
\hline & $(0.005)$ & $(0.026)$ & $(0.009)$ & $(0.068)$ \\
\hline \multirow[t]{2}{*}{ Distance } & $-1.275^{* * *}$ & & $-1.616^{* * *}$ & \\
\hline & $(0.126)$ & & $(0.025)$ & \\
\hline \multirow[t]{2}{*}{ Adjacency } & $0.732^{* * *}$ & & $-0.094^{*}$ & \\
\hline & $(0.340)$ & & $(0.054)$ & \\
\hline \multirow[t]{2}{*}{ Language } & $0.651^{* * *}$ & & $0.683^{* * *}$ & \\
\hline & $(0.313)$ & & $(0.047)$ & \\
\hline \multirow[t]{2}{*}{ EU dummy } & $0.183^{* * *}$ & $0.322^{* * *}$ & & \\
\hline & $(0.020)$ & $(0.022)$ & & \\
\hline \multirow[t]{2}{*}{ EA dummy } & $0.258^{* * *}$ & $0.308^{* * *}$ & & \\
\hline & $(0.202)$ & $(0.021)$ & & \\
\hline \multirow[t]{2}{*}{ AA dummy } & $-0.315^{* * *}$ & $-0.052^{* * *}$ & & \\
\hline & $(0.338)$ & $(0.026)$ & & \\
\hline \multirow[t]{2}{*}{$\mathrm{RPM}$} & & & $0.121^{* * *}$ & -0.011 \\
\hline & & & $(0.019)$ & $(0.020)$ \\
\hline \multirow[t]{2}{*}{ RPMeu } & & & $0.089^{* * *}$ & $0.213^{* * *}$ \\
\hline & & & $(0.031)$ & $(0.025)$ \\
\hline \multirow[t]{2}{*}{ RPMea } & & & $-0.296^{* * *}$ & -0.028 \\
\hline & & & $(0.031)$ & $(0.023)$ \\
\hline \multirow[t]{2}{*}{ RPMaa } & & & $-0.079^{* *}$ & $0.047^{*}$ \\
\hline & & & $(0.034)$ & $(0.027)$ \\
\hline \multirow[t]{2}{*}{ Constant } & $-21.030^{* * *}$ & $-31.590^{* * *}$ & $-.19 .033^{* * *}$ & $-20.094^{* * *}$ \\
\hline & $(0.200)$ & $(1.854)$ & $(0.409)$ & $(2.208)$ \\
\hline No. Obs. & 31812 & 31812 & 10550 & 10550 \\
\hline Adj. $R^{2}$ & 0.747 & 0.931 & 0.792 & 0.952 \\
\hline RMSE & 1.553 & 0.837 & 1.470 & 0.763 \\
\hline Exporter & & yes & & yes \\
\hline Importer & & yes & & yes \\
\hline Time & & yes & & yes \\
\hline Exporter*Importer & & yes & & yes \\
\hline
\end{tabular}

Notes: ${ }^{* * *}$ Denotes significance at the $1 \%$ level; ${ }^{* *}$ denotes significance at the $5 \%$ level. (Robust) standard errors in parentheses. 


\begin{tabular}{|c|c|c|c|c|}
\hline Table 2 - Gravity 1 & \multicolumn{2}{|c|}{ Baseline } & \multicolumn{2}{|c|}{ Continuous variable } \\
\hline Regressors & OLSd & CFEd & OLScv & CFEcv \\
\hline \multirow[t]{2}{*}{ GDP size } & $1.903^{* * *}$ & $0.963^{* * *}$ & $1.880^{* * *}$ & $0.952^{* * *}$ \\
\hline & $(0.008)$ & $(0.045)$ & $(0.016)$ & $(0.106)$ \\
\hline \multirow[t]{2}{*}{ GDP similarity } & $1.057^{* * *}$ & $0.680^{* * *}$ & $0.984^{* * *}$ & $0.835^{* * *}$ \\
\hline & $(0.009)$ & $(0.051)$ & $(0.018)$ & $(0.102)$ \\
\hline \multirow[t]{2}{*}{ GDP pc difference } & $-0.121^{* * *}$ & $-0.060^{* *}$ & $-0.284^{* * *}$ & $-0.232^{* * *}$ \\
\hline & $(0.010)$ & $(0.031)$ & $(0.019)$ & $(0.059)$ \\
\hline \multirow[t]{2}{*}{ Distance } & $-1.355^{* * *}$ & & $-1.505^{* * *}$ & \\
\hline & $(0.013)$ & & $(0.027)$ & \\
\hline \multirow[t]{2}{*}{ Adjacency } & $0.562^{* * *}$ & & $-0.118^{* *}$ & \\
\hline & $(0.034)$ & & $(0.053)$ & \\
\hline \multirow[t]{2}{*}{ Language } & $0.571^{* * *}$ & & $0.677^{* * *}$ & \\
\hline & $(0.032)$ & & $(0.048)$ & \\
\hline \multirow[t]{2}{*}{ EU dummy } & $0.047^{* *}$ & $0.285^{* * *}$ & & \\
\hline & $(0.0219)$ & $(0.235)$ & & \\
\hline \multirow[t]{2}{*}{ EA dummy } & $0.317^{* * *}$ & $0.287^{* * *}$ & & \\
\hline & $(0.020)$ & $(0.021)$ & & \\
\hline \multirow[t]{2}{*}{ AA dummy } & $-0.238^{* * *}$ & $-0.018^{* *}$ & & \\
\hline & $(0.035)$ & $(0.026)$ & & \\
\hline \multirow[t]{2}{*}{ RPM } & & & $0.096^{* * *}$ & -0.015 \\
\hline & & & $(0.020)$ & $(0.020)$ \\
\hline \multirow[t]{2}{*}{ RPMeu } & & & $0.088^{* * *}$ & $0.221^{* * *}$ \\
\hline & & & $(0.029)$ & $(0.249)$ \\
\hline \multirow[t]{2}{*}{ RPMea } & & & $-0.095^{* * *}$ & -0.022 \\
\hline & & & $(0.034)$ & $(0.022)$ \\
\hline \multirow[t]{2}{*}{ RPMaa } & & & 0.052 & $0.051^{*}$ \\
\hline & & & $(0.036)$ & $(0.027)$ \\
\hline \multirow[t]{2}{*}{ Constant } & $-20.161^{* * *}$ & $-16.582^{* * *}$ & $-18.389 * * *$ & 1.321 \\
\hline & $(0.200)$ & $(2.036)$ & $(0.443)$ & $(2.397)$ \\
\hline No. Obs. & 31812 & 31812 & 10550 & 10550 \\
\hline Adj. $R^{2}$ & 0.735 & 0.931 & 0.787 & 0.953 \\
\hline RMSE & 1.589 & 0.836 & 1.490 & 0.759 \\
\hline Exporter; Importer & & yes & & yes \\
\hline Time; country pair & & yes & & yes \\
\hline
\end{tabular}

Notes: ${ }^{* * *}$ Denotes significance at the $1 \%$ level; ${ }^{* *}$ denotes significance at the $5 \%$ level. (Robust) standard errors in parentheses.

The third and fourth columns of Tables 1 and 2 report the outcomes of the continuous variable strategy. As expected, the significance of the CFE specification also under this strategy is higher than with the dummy strategy (both the adjusted $\mathrm{R}^{2}$ and the RMSE test improved). Moreover, the estimates confirm the robustness and the positive impact of the EU trade preferences granted both in the context of the European Single Market membership (RPMeu) and - 
to a lesser extent - of the current EU-MED Association Agreements (RPMaa). It should also be noted that the CFE specification of the continuous strategy correctly highlights a positive sign for the preferential margin of the EU-MED association agreements. It refines the policy impact of the tariff preference from the actual influences of the trading obstacles still in place between MED and

\section{EU countries.}

However, the continuous variable estimates do not support the assumption of a positive impact of the EU trade policy in the context of the EU trade integration process towards CEECs before the enlargement (RPMea).This suggests that, in the case of the EU-CEECs "full partnership without membership", trade policy probably was not the primary factor behind the observed expansion in bilateral trade. Other factors have been more important in these initial EU efforts towards deep integration with Eastern partner countries (a result first suggested by Fernandez and Portes, 1998).

To shed light on these additional trade enhancing factors other than trade preferences, we apply our nonparametric Abadie and Imbens (2006) matching estimator (A-I) to the same dataset. As already stated, it represents a more robust and reliable measure of the long term average (partial) treatment effect. It is more suited to assessing the trade impact of the complex experience of deep integration, as in the case of ENP, since it solves both the non-random selection bias and the likely presence of non-linearities in the relation between policy treatment and bilateral trade flows. As it is apparent in Fig. 1A and 2A, our matching exercise is successful. If we compare the kernel density function of the gravity equation covariates (for brevity Figs. 1A and 2A only present the outcomes for the log bilateral distance and GDP) the distribution of treated pairs differ substantively from those of the untreated pairs before the matching, while the two distributions are virtually indistinguishable after the matching.

Table 3 presents the outcomes of our (A-I) matching estimator compared with that of the baseline scenario (only CFE gravity estimates are given for brevity), both for standard and NTT covariates. It has to be noted first that the A-I ATE estimates are as robust as the corresponding gravity estimates but larger in magnitude for any policy treatment effects. A similar pattern occurs when using the A-I ATT estimators, except in the case of EA. This estimator is a more sensible measure of the actual magnitude of the EU treatment effect for policymaking, being an average of ATT and ATU (Average Treatment effect on the Untreated pairs). These results strongly confirm, on the one hand, the large impact of the internal market harmonization policies on bilateral trade flows (ATT A-I EU is larger than the related coefficient for RPM) and, on the other hand, the likely presence of obstacles responsible for widening the trade gap between EU members and SMCs (ATT A-I AA is significantly negative while the related coefficient for RPM is positive). 


\begin{tabular}{|c|c|c|}
\hline \multicolumn{3}{|c|}{ Table 3 - Policy treatment effects } \\
\hline Effects & Standard gravity covariates & NTT gravity covariates \\
\hline \multirow[t]{2}{*}{ ATE CFE EA } & $0.308^{* * *}$ & $0.287^{* * *}$ \\
\hline & $(0.021)$ & $(0.021)$ \\
\hline \multirow[t]{2}{*}{ ATE CFE AA } & $-0.052^{* * *}$ & $-0.018^{* *}$ \\
\hline & $(0.026)$ & $(0.026)$ \\
\hline \multirow[t]{2}{*}{ ATE CFE EU } & $0.322^{* * *}$ & $0.285^{* * *}$ \\
\hline & $(0.022)$ & $(0.235)$ \\
\hline \multirow[t]{2}{*}{ RPM CFE EA } & -0.028 & -0.022 \\
\hline & $(0.023)$ & $(0.022)$ \\
\hline \multirow[t]{2}{*}{ RPM CFE AA } & $0.047^{*}$ & $0.051^{*}$ \\
\hline & $(0.027)$ & $(0.027)$ \\
\hline \multirow[t]{2}{*}{ RPM CFE EU } & $0.213^{* * *}$ & $0.221^{* * *}$ \\
\hline & $(0.025)$ & $(0.249)$ \\
\hline \multirow[t]{2}{*}{ ATE A-I EA } & $0.486^{* * *}$ & $0.518^{* * *}$ \\
\hline & $(0.067)$ & $(0.072)$ \\
\hline \multirow[t]{2}{*}{ ATE A-I AA } & $-0.196^{* * *}$ & $-0.110^{*}$ \\
\hline & $(0.067)$ & $(0.070)$ \\
\hline \multirow[t]{2}{*}{ ATE A-I EU } & $1.059^{* * *}$ & $1.272^{* * *}$ \\
\hline & $(0.080)$ & $(0.105)$ \\
\hline \multirow[t]{2}{*}{ ATT A-I EA } & $0.278^{* * *}$ & $0.379^{* * *}$ \\
\hline & $(0.029)$ & $(0.033)$ \\
\hline \multirow[t]{2}{*}{ ATT A-I AA } & $-0.265^{* * *}$ & $-0.126^{* * *}$ \\
\hline & $(0.040)$ & $(0.050)$ \\
\hline \multirow[t]{2}{*}{ ATT A-I EU } & $0.557^{* * *}$ & $0.554^{* * *}$ \\
\hline & $(0.031)$ & $(0.039)$ \\
\hline
\end{tabular}

Focusing on EA, it has to be noted as well that the estimated ATE is positive and statistically significant from zero both in parametric and nonparametric estimations. This result removes any doubt about the trade enhancing impact of EAs on EU-CEECs bilateral flows. However, the ATT A-I estimator of EA is lower than both the gravity and the A-I ATEs, even if it is still high, statistically robust and positive. Hence, our empirical outcomes strongly confirm the robust and positive impact of the EAs "treatment" on bilateral trade flows among the "treated" EU-CEECs countries. More specifically, we can estimate a trade enhancing effect of EAs of about 30 per cent $\left(e^{0.278}=1.3204\right)$. At the same time, it shows that this positive impact on bilateral trade is not related to trade preferences (the trade impact of granted preferential margins is not significantly different from zero), but rather to additional factors linked to the EU effort towards a deep integration with CEECs. This is the most interesting empirical result of our analysis. It suggests that the new deep integration effort carried out by the EU through ENP is likely to have a clear trade enhancing impact on current EU-MED FTA, even in the absence of trade preferences. 


\section{EU-MED trade potential before and after ENP}

We are now in a position to provide an up-to-date picture of the actual trade potential within the EU MED partnership. First, we provide a measure of the actual gap between observed and potential trade flows (i.e., flows predicted by our "in sample" empirical estimates) for each EU-SMC country pairs. Potential trade flows - and the corresponding trade gaps with observed data - are the predicted bilateral export flows computed using both gravity estimations and the A-I ATT estimators for the "policy treatments" currently in place between EU and SMCs. Trade gaps are calculated as the percent ratio of the observed bilateral trade flows over the predicted export flows. This is our trade potential index. This index takes the value of 1 if the two flows (observed and predicted) are fully balanced; a value less than 1 if the observed flows are less than the predicted ones (i.e., trade obstacles still hold); a value larger than 1 if observed trade is larger than the predicted one (i.e., bilateral trade is higher than its potential). Figures $3 \mathrm{~A}$ and $4 \mathrm{~A}$ show the performance of our trade potential index for each SMC over the entire period under investigation. As shown in previous analyses, the actual export flows of SMCs towards EU are, on average, consistent with their trade potentials. This is evident in both the standard and the NTT gravity estimates. It is worth noting, however, a tendency towards a reduction of the gap (i.e., an increasing trend of our index) in the case of Egypt, Jordan and Turkey with respect to the new EU member partners, while the opposite happens in the case of Algeria. The peculiar situation of Israel must be mentioned as well which recently - in countertendency with the other Mediterranean partners - enlarged its gap between actual and potential exports.

We can go further and provide a tentative picture of bilateral trade flows in the case of the full implementation of the EU-MED "full partnership without membership" scenario, simply by applying the above "in sample" estimates to a ten year forward projection of trade flows, assuming the ATT of ENP to be proportional to our robust A-I EA estimates. As already stated, our empirical results strongly confirm the presence of a robust and positive trade impact of the past experience of "full partnership without membership" linked to additional factors than trade preferences, most likely induced by EU efforts toward deep integration with CEECs. Since the same effort is declared by the EU in carrying out the new ENP with SMCs beneficiaries, it is reasonable to take advantage of all the information we can get from available past experience to provide a workable simulation of the hypothetical situation of full implementation of ENP. To this end, we compute the hypothetical value of our trade potential index in 2018 (ten years on from 2008, i.e., the last year in our dataset) based on the assumption of full implementation of ENP by that date. Our trade potential index now provides a concrete measure, in percentage points, of the trade enhancing effect of ENP on each bilateral EU-MED country pair. However, simulating potential trade flows ten years on, needs a reasonable hypothesis about the expected GDP growth for each country in the sample. For the sake of simplicity, but not going too far from reality, we decided to apply a 2 percent growth rate for the $\mathrm{EU}$ members and a 4 percent rate for SMCs. These rates are fully in line with 
the World Bank - Global Economic Prospects Report 2011 (The World Bank, 2011). Figures 1 and 2 provide a glance of the hypothetical export performance of each SMC after the full implementation of ENP. The magnitude of the likely impact of ENP in terms of trade integration is represented by the average distance from 1 (a balanced value of our new trade potential index represented by the red line in the figures). Our simulation shows that ENP is not equal in its effect in promoting trade integration between EU member States and their MED partners. All SMCs (particularly in the case of Israel and Turkey) show a balanced trade pattern, with the exception of Algeria and a number of country pairs outliers. This supports the relevance of the EC choice of implementing ENP on a "case by case" strategy, i.e. elaborating detailed Plans of Actions with each bilateral partner. 
Figure 1 - Trade index (actual/potential exports) forecast to 2018. Standard gravity equation
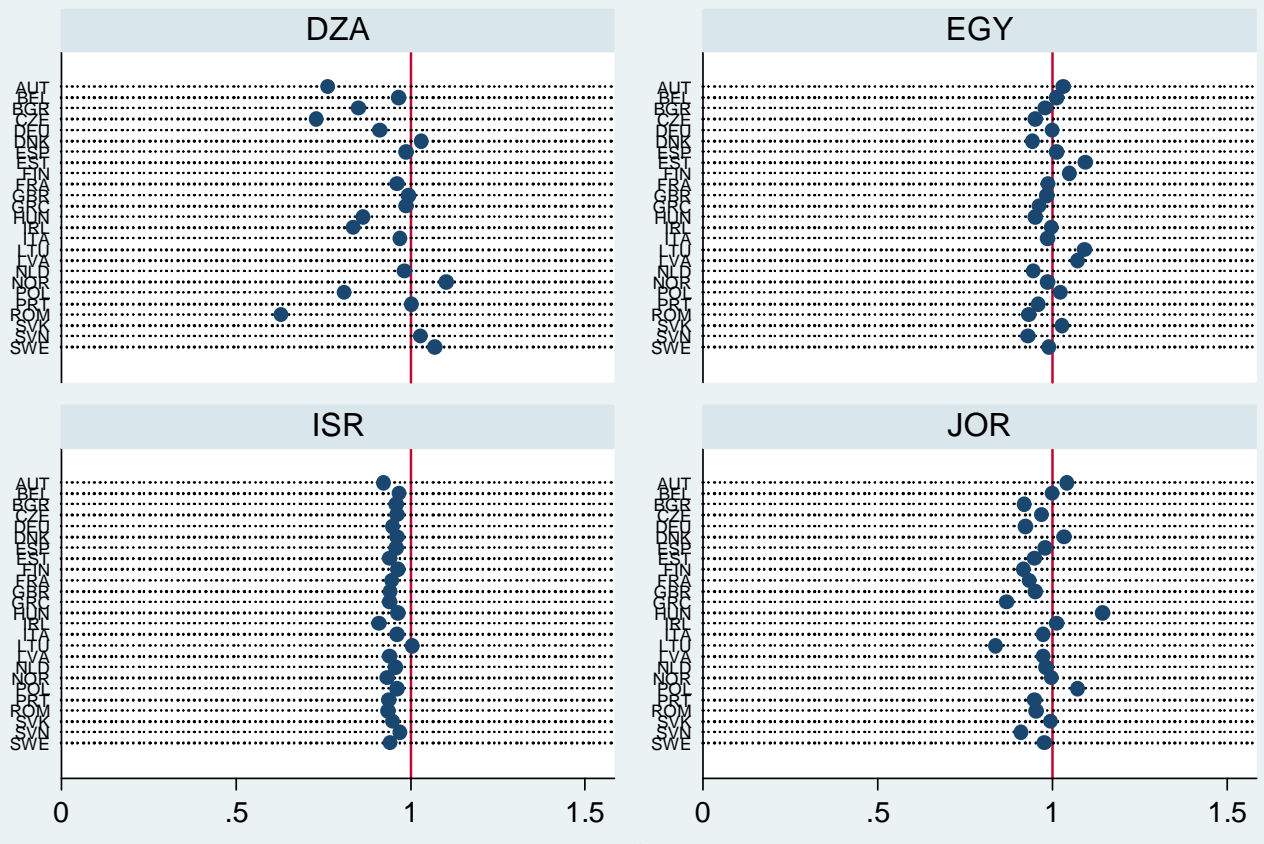

Graphs by reporter

mean of index
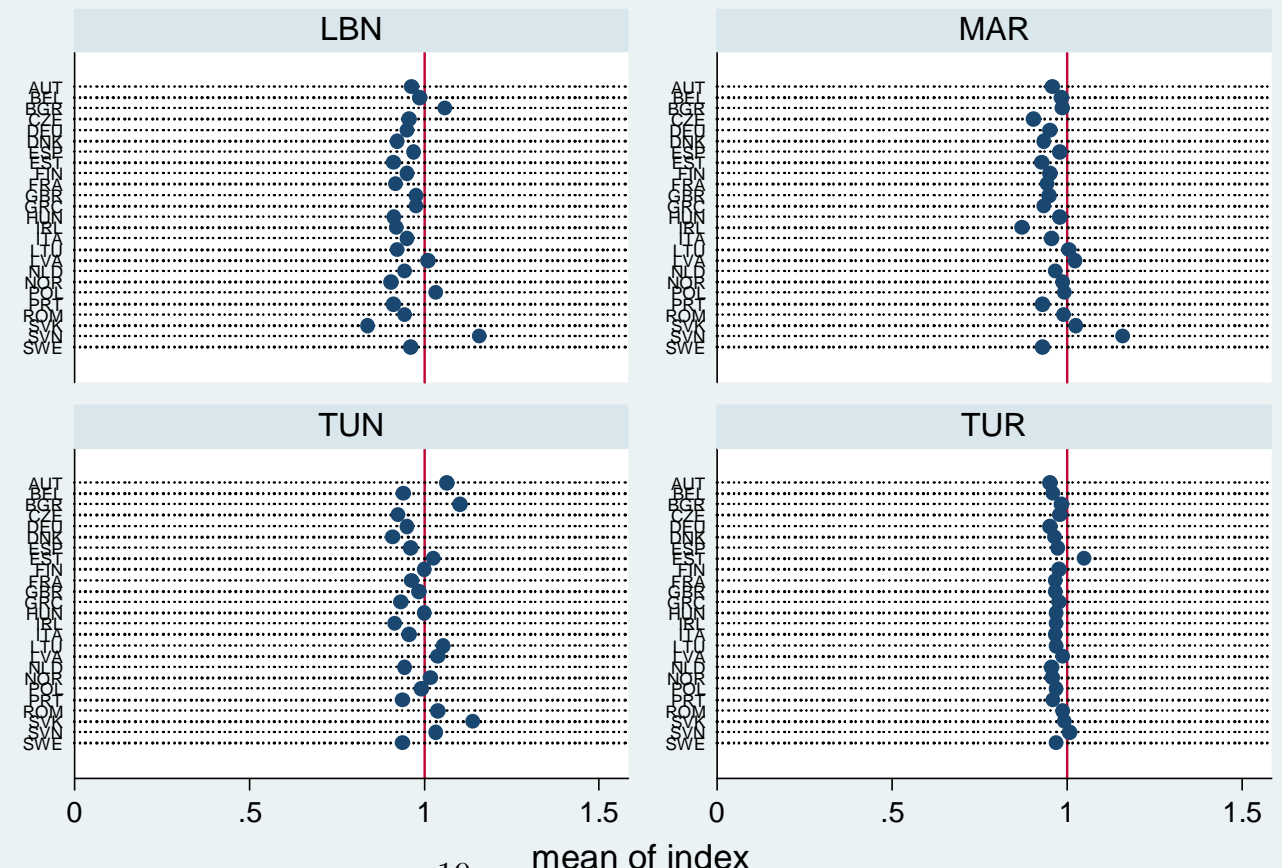

Graphs by reporter

mean of index 
Figure 2 - Trade index (actual/potential exports) forecast to 2018. NTT gravity equation
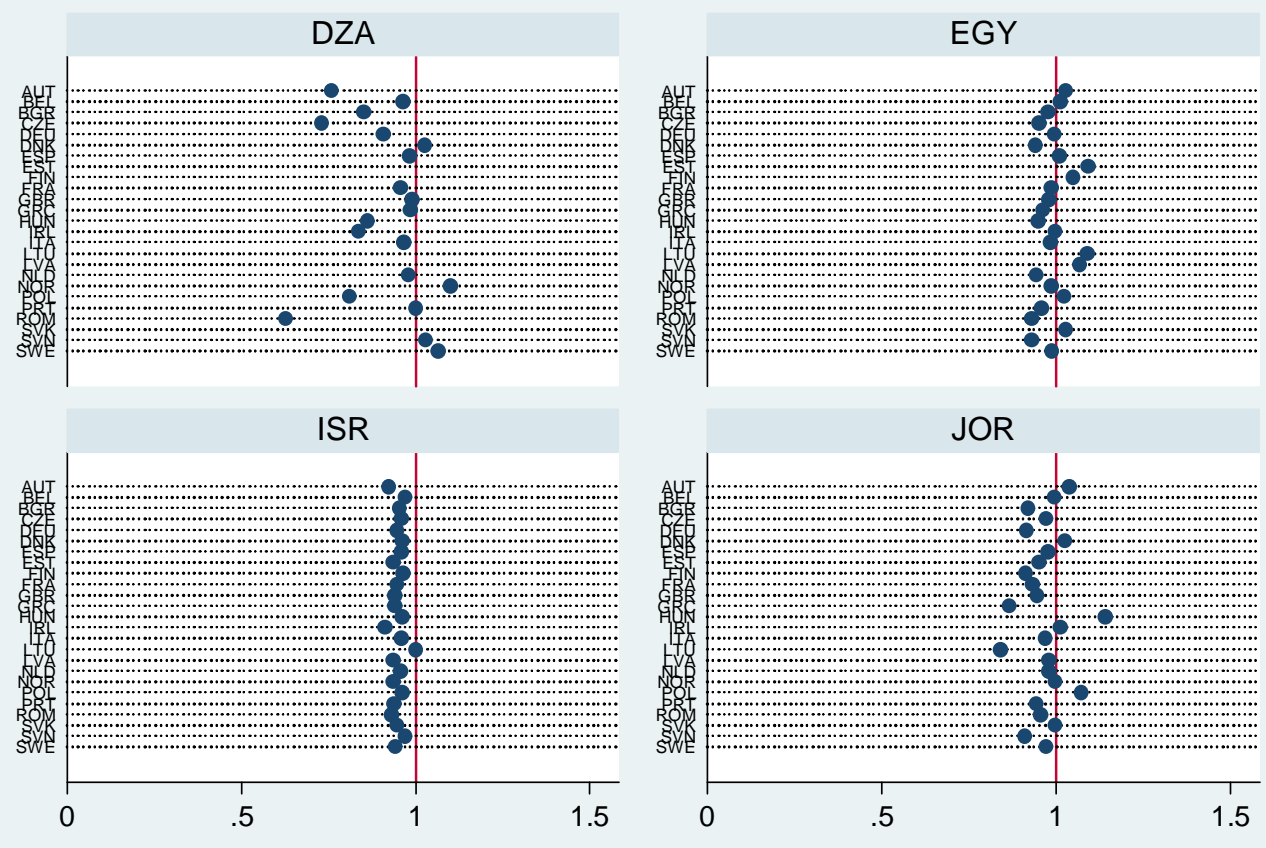

Graphs by reporter
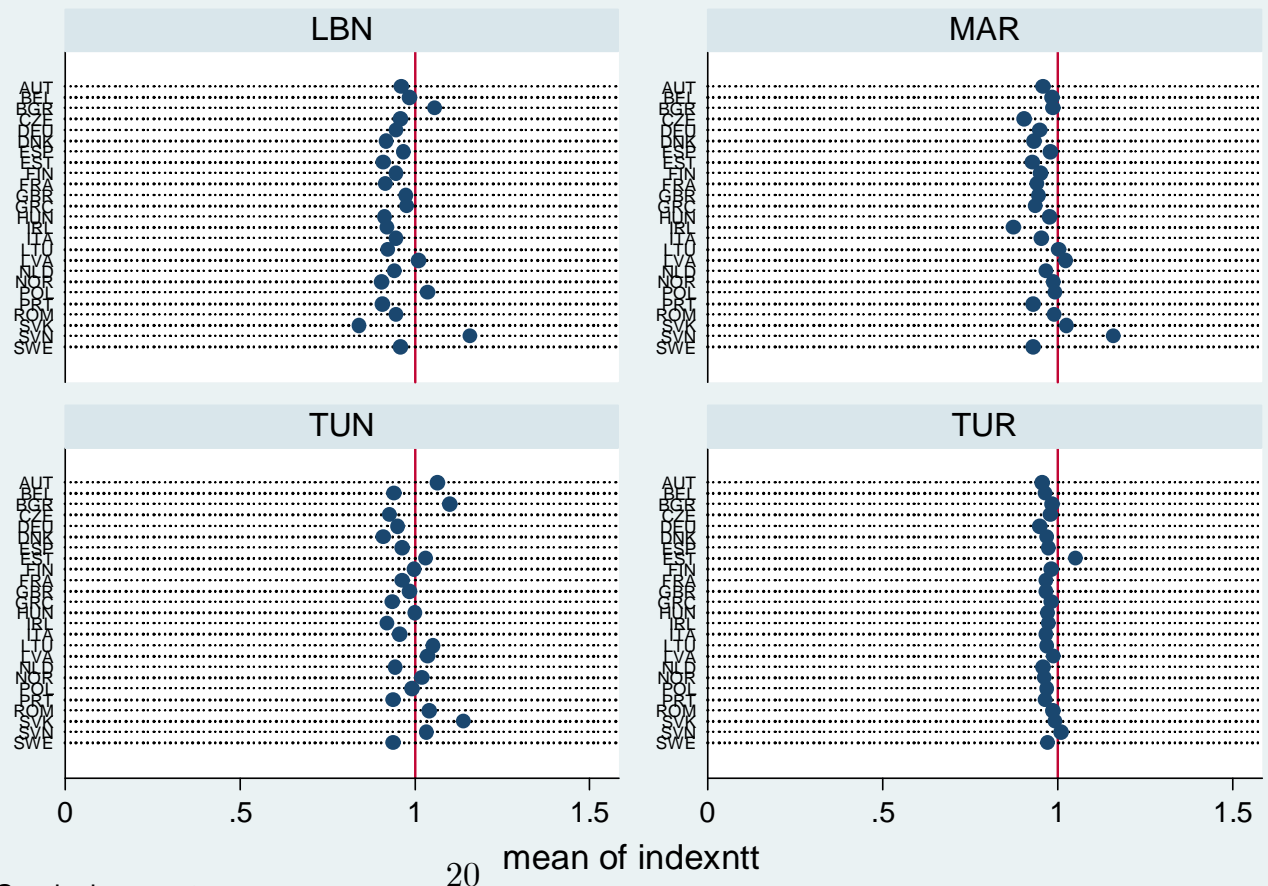

Graphs by reporter 


\section{Concluding remarks}

Will ENP have a significant impact on EU-MED trade integration? Will it determine an actual breakthrough in the current sticky EU-MED partnership? These are the most relevant and timely policy issues in the EU-MED context. This work presents robust estimates (based on gravity and matching econometrics) of the patterns of trade in the EU-MED area and a workable simulation of the likely impact of ENP using "in sample" estimates. By controlling for country and time heterogeneity, using both qualitative and quantitative measures of the policy variable, we demonstrate, on one hand, the trade enhancing impact of ENP, even if not necessarily linked to additional trade preferences, and on the other hand that the trade impact of ENP cannot be taken for granted in every context. Thus, our empirical results present a less pessimistic approach concerning the efficacy of the Pan-European trade integration process, thus supporting the opportunity for a "tailor made" approach in the implementation of ENP action plans.

\section{References}

[1] Abadie, A., and Imbens G., W. (2006). Large sample properties of matching estimators for average treatment effects. Econometrica, 74 (1), 235-267.

[2] Abedini, J., and Péridy, N. (2008) The Greater Arab Free Trade Area (GAFTA): an Estimation of Its Trade Effects. Journal of Economic Integration 23(4): 848-872.

[3] Anderson, J., and Neary, P. (2003). The mercantilist index of trade policy. International Economic Review, 44(2): 627-649.

[4] Anderson, J., E. and van Wincoop, E. (2003). Gravity with Gravitas: A Solution to the Border Puzzle. American Economic Review, 93, 1, 170-192

[5] Baier, S., L. and Bergstrand, J., H. (2004). Economic determinants of free trade agreements. Journal of International Economics, 64, 29- 63

[6] Baier, S., L. and Bergstrand, J., H. (2007). Do free trade agreement actually increase members' international trade?. Journal of International Economics, 71(1), 72-95

[7] Baier, S., L. and Bergstrand, J., H. (2009). Estimating the effects of free trade agreements on international trade flows using matching econometrics. Journal of International Economics, 77, 63-76

[8] Baldwin, R., E. and Taglioni D. (2006). Gravity for Dummies and Dummies for Gravity Equations. NBER Working Papers 12516, National Bureau of Economic Research 
[9] Baldwin, R., E. and Taglioni D. (2007). Trade Effects of the Euro: A Comparison of Estimators. Journal of Economic Integration, 22(4): 780

[10] Baltagi, B., Egger, H., P., and Pfaffermayr M. (2003). A Generalized Design for Bilateral Trade Flow Models. Economics Letters, 80(3): 391-97

[11] Bensassi, S., Martinez-Zarzoso, I., and Marquez-Ramos, L.(2010). Economic integration and the two margins of trade: An application to the Euro-Mediterranean agreements. CREMed WP 2/2010

[12] Bergstrand, J., H. (1985) The Gravity Equation in International Trade: Some Microeconomic Foundations and Empirical Evidence. Review of Economic Statistics, 67

[13] Bergstrand, J., H. (1990) The Heckscher-Ohlin-Samuelson model, the Linder hypothesis and the determinants of bilateral intra-industry trade. Economic Journal, 100, 1216-1229

[14] Cardwell, P., J. (2011). EuroMed, European Neighbourhood Policy and the Union for the Mediterranean: Overlapping Policy Frames in the EU's Governance of the Mediterranean. Journal of Common Market Studies, 49(2), 219-241

[15] CASE-CEPS (L. de Wulf and M. Maliszewska eds.) (2009), Economic Integration in the Euro-Mediterranean Region. CASE-CSER report.

[16] Cipollina, M., and Salvatici, L. (2010). Reciprocal Trade Agreements in Gravity Models: A Meta-Analysis. Review of International Economics, 18(1), 63-80

[17] Cipollina, M., and Salvatici, L. (2011). European Union Preferential Margins Measurement and Aggregation Issues, in De Benedictis, L., and Salvatici, L., The Trade Impact of European Union Preferential Policies: An Analysis Through Gravity Models, Springer.

[18] De Benedictis, L., and Vicarelli, C. (2005). "Trade Potentials in Gravity Panel Data Models". Topics in Economic Analysis 8 Policy, 5(1)

[19] De Benedictis, L., and Taglioni, D. (2011). The Gravity Model in International Trade, in De Benedictis, L., and Salvatici, L., The Trade Impact of European Union Preferential Policies: An Analysis Through Gravity Models, Springer.

[20] Deardoff, A. (1997). "Determinants of Bilateral Trade: Does Gravity work in a Classical Word?", The Regionalisation of the World Economy, ed.Frankel J., University of Chicago Press

[21] Del Sarto, R., A., and Schumacher, T. (2005). From EMP to ENP : what's at stake with the European neighbourhood policy towards the southern Mediterranean?, European Foreign Affairs Review, v. 10, n. 1, Spring, p. [17]-38 
[22] EC (2011). A new response to a changing Neighbourhood, Joint Communication to the European Parliament, the Council, the European Economic And Social Committee and the Committee of the Regions, COM(2011) 303;

[23] Egger, P. (2000). "A Note on the Proper Econometric Specification of the Gravity Equation". Economics Letters, vol. 66, 25-31.

[24] Egger, P. (2004). "On the Problem of Endogenous Unobserved Effects in the Estimation of Gravity Models". Journal of Economic Integration, vol. 19, 182-191.

[25] Egger, P. and Pfaffermayr, M., (2003). The Proper Panel Econometric Speci.cation of the Gravity Equation: A Three-way Model with Bilateral Interaction Effects. Empirical Economics, 28(3), 571-80

[26] Feenstra, R., C. (2002). Border Effects and the Gravity Equation: Consistent Methods for Estimation. Scottish Journal of Political Economy, 49(5), 491-506.

[27] Femise (various years). Report on the Euro-Mediterranean Partnership. Marseille: Femise

[28] Fernandez, R., and J., Portes (1998). Returns to Regionalism: An Analysis of Nontraditional Gains from Regional Trade Agreements. The World Bank Economic Review, 12 (2): 197-220

[29] Francois, J., Hoekman, B., and Manchin, M. (2006). Preference erosion and multilateral trade liberalization. The World Bank Economic Review, $20: 197-216$

[30] Glick, R., and Rose, A., K. (2001). Does a Currency Union Affect Trade? The Time-Series Evidence. National Bureau of Economic Research Working Paper No. 8396, July.

[31] Hagemejer, J., and Cieslik, A. (2009). Assessing the impact of the EUsponsored trade liberalization in the MENA countries. Journal of Economic Integration, 24(2): 344-369.

[32] Helpman, E., Krugman, P., R. (1985). Market structure and Foreign Trade. MIT Press, Cambridge MA

[33] Helpman, E. (1987). Imperfect competition and international trade: Evidence from fourteen industrial countries. Journal of the Japanese and the International Economies, 1(1), 62-81.

[34] Hoekman, B., and Nicita, A. (2011). Trade Policy, Trade Costs, and Developing Country Trade, World Development, 39(12), 2069-2079.

[35] Hornok, C. (2011). Gravity or Dummies? The Limits of Identification in Gravity Estimations. CeFiG Working Papers 15, Center for Firms in the Global Economy 
[36] Hummels, D., and Levinsohn, J. (1995). Monopolistic competition and international trade: Reconsidering the evidence. Quarterly Journal of Economics, 110 (3), 799-836.

[37] Kee, H., L., Nicita, A., and Olarreaga, M. (2009). Import demand elasticities and trade distortions. Review of Economics and Statistics, 90(4), 666-682.

[38] Krugman, P., R. (1980). Scale economies, product differentiation, and the pattern of trade. American Economic Review, 70, 950-959.

[39] Jarreau, J. (2011). Economic integration in the EuroMed: current status and review of studies, CEPII, WP No 2011-07

[40] Low, P., Piermartini, R., and J., Richtering (2008) Multilateral Solutions to the Erosion of Non-Reciprocal Preferences in NAMA. In Hoekman, B., Martin, W., and Primo Braga, C. (eds.), Trade Preference Erosion, Palgrave-McMillan.

[41] Mátyás, L. (1997). Proper Econometric Specification of the Gravity Model, The World Economy, 20, 3, 363-68

[42] Milcher, S., Slay, B., and Collins, M. (2007). The Economic Rationale of the "European Neighbourhood Policy". In: Ålsund, A., (ed.), Europe after Enlargement, Cambridge University Press, Cambridge, 165-188.

[43] Pastore, F., Ferragina, A., Giovannetti, G. (2009). A Tale of Parallel Integration Processes: A Gravity Analysis of the EU Trade with Mediterranean and Central and Eastern European Countries, Review of Middle East Ecomics and Finance, Berkeley Electronic Press, 5(2)

[44] Persson, T., (2001). Currency unions and trade: how large is the treatment effect?, Economic Policy, 435-448.

[45] Rose, A., and van Wincoop, E. (2001). National Money as a Barrier to Inter-national Trade: The Real Case for Currency Union, American Economic Review, 91, 2, 386-390.

[46] Ruiz, J., M. and Vilarrubia J., M. (2007). The Wise Use of Dummies in Gravity Models: Export Potentials in the Euro-Med Region, Bank of Spain Working Paper, No. 0720.

[47] Stack, M. (2009). Regional integration and trade: Controlling for varying degrees of heterogeneity in the gravity model, The World Economy, 32(5), $772-789$

[48] The World Bank (2011) Global Economic Prospects. Maintaining progress amid turmoil, Vol. 3, June, Washington DC

[49] Tinbergen, J. (1962). Shaping the World Economy, New York: Twentieth Century Fund. 


\section{Appendix}

\begin{tabular}{|c|c|c|}
\hline \multicolumn{3}{|c|}{$\begin{array}{l}\text { Table 1A - The Europe Agreements } \\
\end{array}$} \\
\hline Country & Europe Agreement signature date & Entry into force \\
\hline Bulgaria & March 1993 & February 1995 \\
\hline Czech Republic & October 1993 & February 1995 \\
\hline Estonia & June 1993 & February 1998 \\
\hline Hungary & December 1991 & February 1994 \\
\hline Latvia & June 1995 & February 1998 \\
\hline Lithuania & June 1995 & February 1998 \\
\hline Poland & December 1991 & February 1994 \\
\hline Romania & February 1993 & February 1995 \\
\hline Slovakia & October 1993 & February 1995 \\
\hline Slovenia & June 1996 & February 1999 \\
\hline
\end{tabular}

\begin{tabular}{|c|c|c|}
\hline \multicolumn{3}{|c|}{ Table 2A - The Euro-Mediterranean Association Agreements } \\
\hline Country & Signature date & Entry into force \\
\hline Algeria & 22 April 2002 & 1 September 2005 \\
\hline Egypt & 25 June 2001 & $1 \mathrm{June} 2004$ \\
\hline Israel & 20 November 1995 & 1 June 2000 \\
\hline Jordan & 24 November 1997 & 1 May 2002 \\
\hline Lebanon & 17 June 2002 & 1 April 2006 \\
\hline Morocco & 26 February 1996 & $1 \mathrm{March} 2000$ \\
\hline Palestinian Authority & 24 February 1997 & 1 July 1997 (Interim association agreement) \\
\hline Syria & Negotiations concluded awaiting for signature & \\
\hline Tunisia & 17 July 1995 & $1 \mathrm{March} 1998$ \\
\hline Turkey & 6 March 1995 & 31 December 1995 \\
\hline
\end{tabular}




\begin{tabular}{|l|}
\hline \hline Table 3A - Countries in the Sample \\
\hline \hline Exporters (42 countries): \\
\hline EEA+1: \\
France (FRA), Italy (ITA), Germany (DEU), Spain (ESP), United Kingdom (GBR), Portugal (PRT), \\
Greece (GRC), Austria (AUT), Sweden (SWE), Finland (FIN), Belgium-Luxembourg (BEL), \\
Denmark (DNK), Ireland (IRL), Netherlands (NLD), Norway (NOR), Switzerland (CHE) \\
\hline CEECs: \\
\hline Bulgaria (BGR), Czech Republic (CZE), Estonia (EST), Hungary (HUN), Latvia (LVA), \\
\hline Lithuania (LTU), Poland (POL), Romania (ROM), Slovakia (SVK), Slovenia (SVN) \\
\hline MED+1: \\
\hline Algeria (DZA), Egypt (EGY), Israel (ISR), Jordan (JOR), Lebanon (LBN), \\
\hline Morocco (MAR), Syria (SYR), Tunisia (TUN), Turkey (TUR) \\
\hline NiS+1: \\
\hline Armenia (ARM), Azerbaijan (AZE), Belarus (BLR), Georgia (GEO), \\
\hline Moldova (MDA), Ukraine (UKR), Russian Federation (RUS) \\
\hline \hline Importers (49 countries, the same exporters plus the following main world partners): \\
\hline \hline United States (USA), China (CHN), Japan (JPN), Brazil (BRA), \\
\hline India (IND), Korea (Republic of South - KOR), Canada (CAN) \\
\hline
\end{tabular}

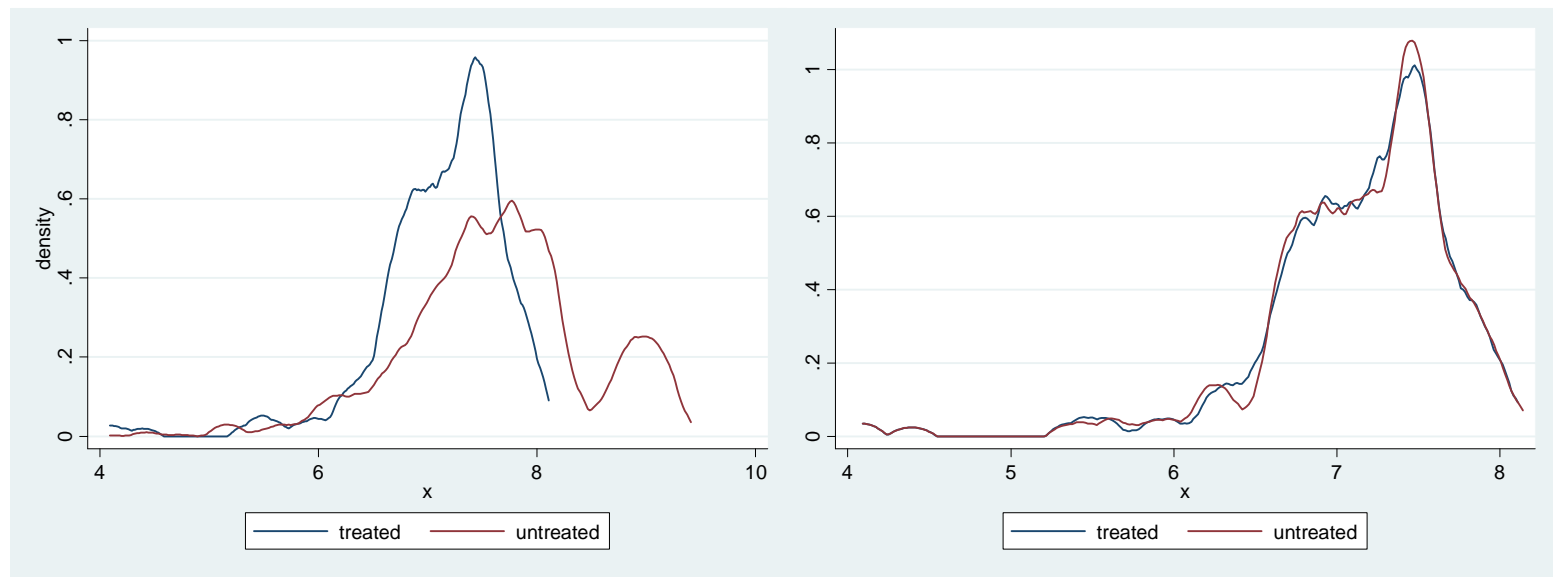

Figure 1A - Log of distance for bilateral pairs pre and post matching 

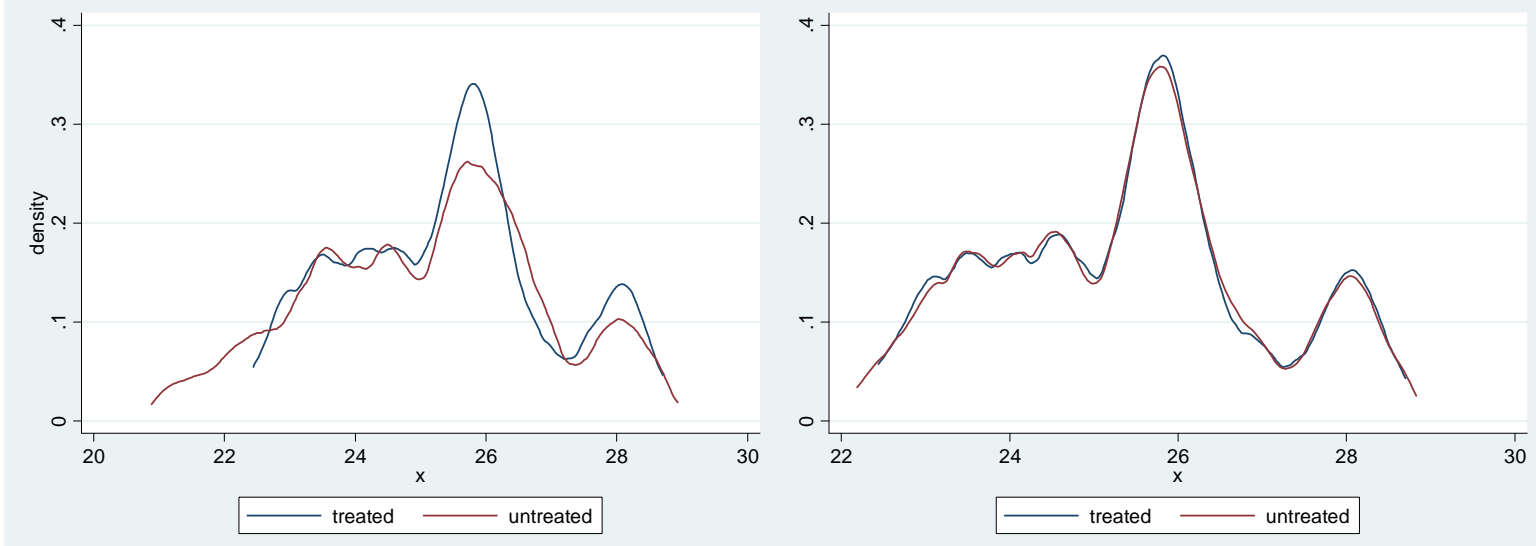

Figure 2A - Log of GDP for bilateral pairs pre and post matching 
Figure 3A - Trade index (actual/potential exports). Standard gravity equation, 1992-2008
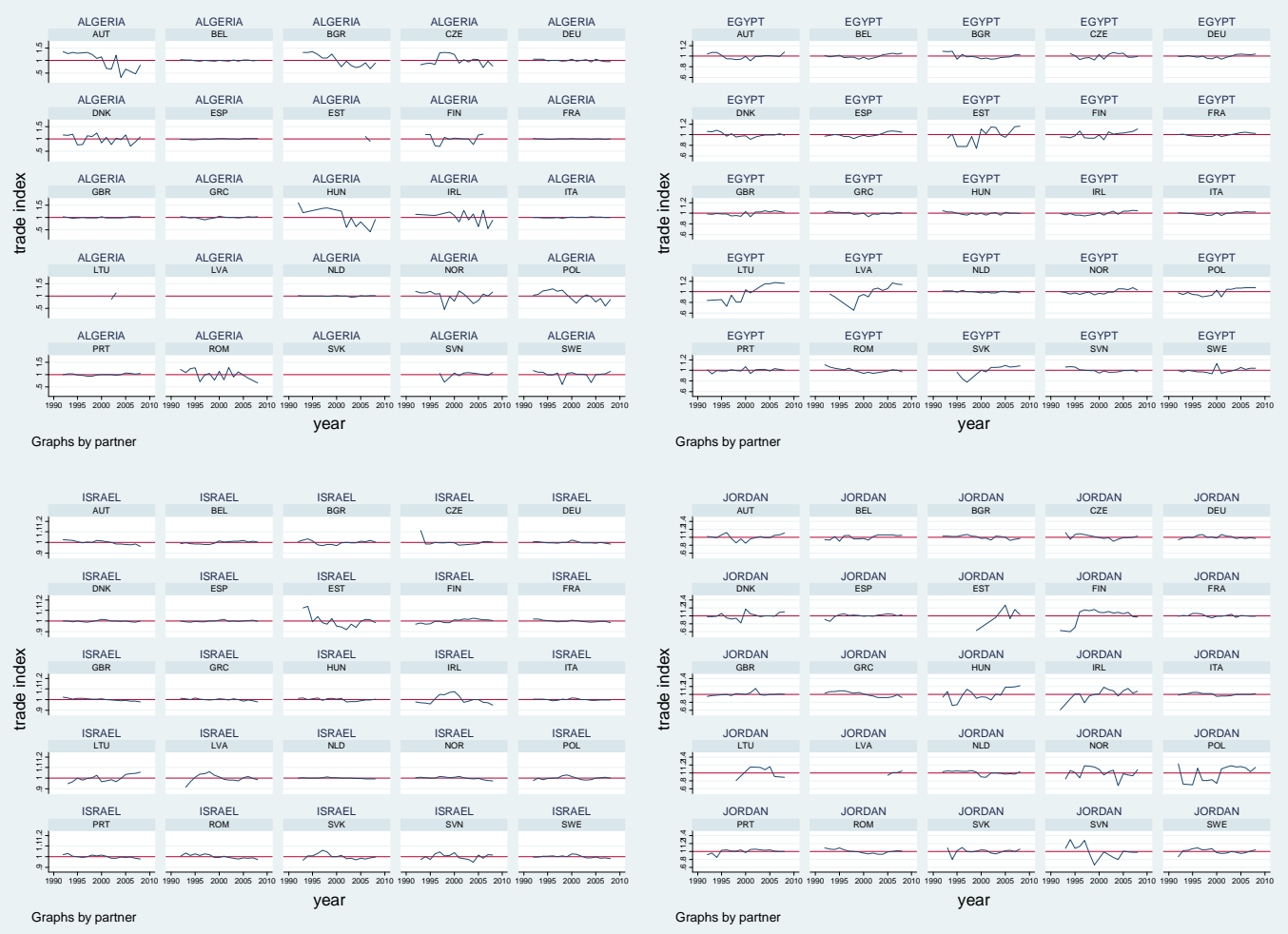

Graphs by partner
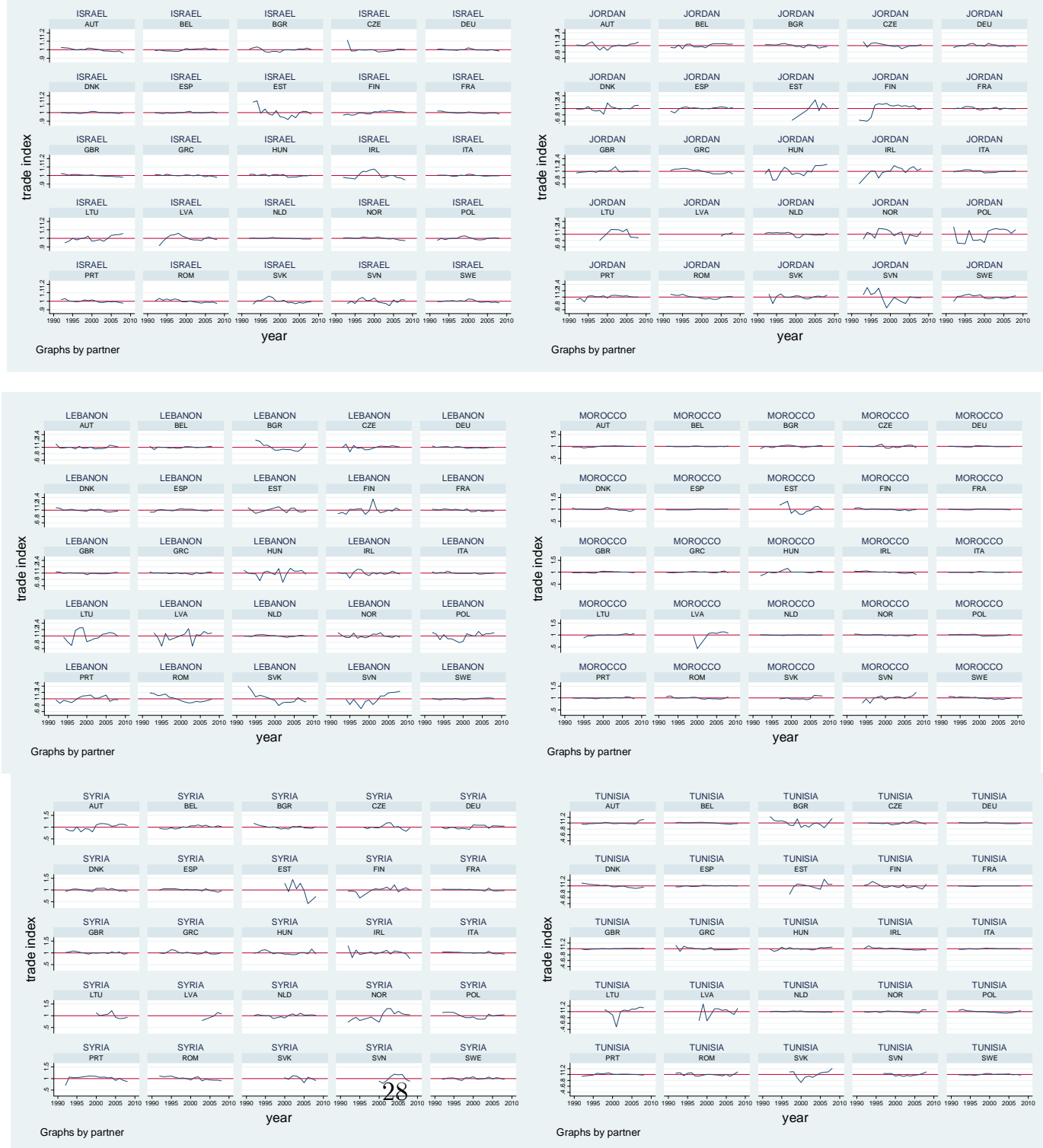


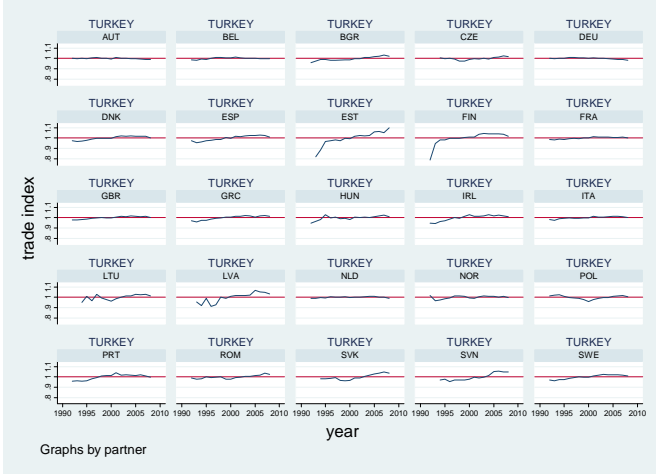


Figure 4A - Trade index (actual/potential exports). NTT gravity equation, 1992-2008
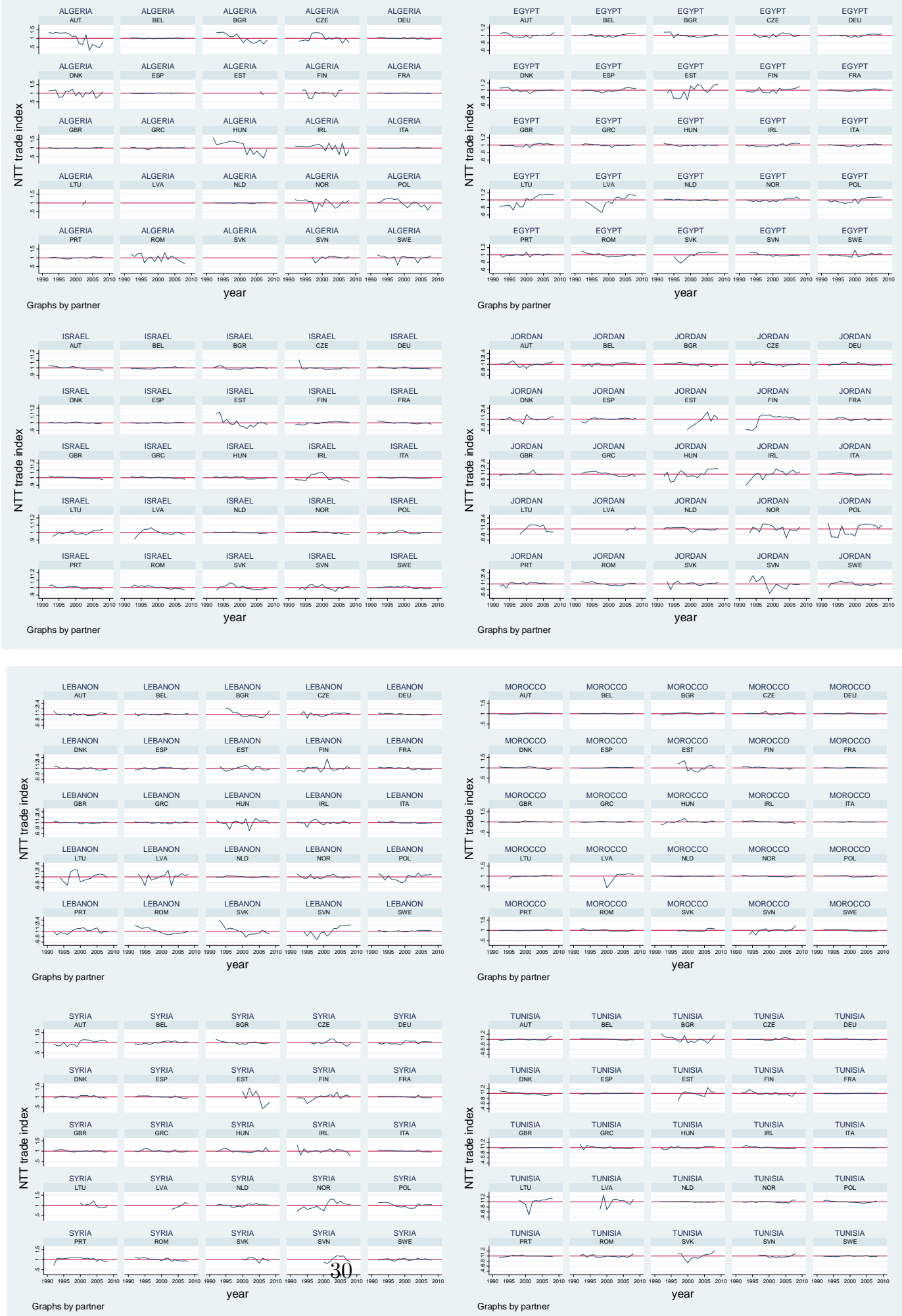


TUER

